\title{
Solid Particle Erosion Characteristics of Composites Filled with Nano Carbon Fibers
}

\author{
Bao Limin ${ }^{\mathrm{a}, *}$, Qian Danna ${ }^{\mathrm{a}}$, Wang Guoyu ${ }^{\mathrm{b}}, \mathrm{KemmochI}^{\mathrm{K}}$ Kiyoshi ${ }^{\mathrm{a}}$ \\ ${ }^{a}$ Faculty of Textile Science and Technology, Shinshu University, 3-15-1, Tokida, Ueda-shi, Nagano, 386-8567, Japan \\ ${ }^{\mathrm{b}}$ School of Textiles, Tianjin Polytechnic University, Tianjin 300160, China
}

Received 12 September 2011; accepted for publication 3 February 2012

\begin{abstract}
The solid particle erosion characteristics of the body materials used in high-speed moving equipment have attracted wide attention from researchers. In the last few years, nanofiller/polymer composites have been widely investigated in academia and industry because of their outstanding multifunction properties. In order to enhance the erosion resistance of existing materials and to develop new composite materials with high strength and excellent erosion resistance, we attempted to use nano carbon fiber (VGCF) with high strength and high modulus as filler for reinforcing UP resin matrix. This study investigated the effects of the filler weight content, impact angle, and impact velocity on the erosion wear characteristics of UP resin composite materials. The mechanical properties of composite materials reinforced by VGCF were also evaluated. The results indicate that it is feasible to simultaneously improve the erosion resistance and mechanical properties of UP resin by using VGCF filler.
\end{abstract}

Key Words: Dry sand erosion, Wear, UP resin, VGCF, Mechanical properties

\section{INTRODUCTION}

Composite materials have been widely used in various engineering fields as well as for aerospace and marine applications. It has been reported that various applications of composite materials in equipment expose it to erosion wear conditions and that the surface of this equipment will be impacted by solid particles contained in the air or liquids, destroying the material.

Due to the operational requirements of dusty environments, the erosion characteristics of composite materials are vitally important and have attracted much attention from researchers. A.P. Harsha et al. [1] summarized and listed erosion experiments involving polymer composites. The erosion resistance of glass and carbon fiber-reinforced polymer has been investigated by many groups [2-7]. According to the related literature, it is widely recognized that polymer composites containing reinforcement fiber usually erode faster than neat polymers [1, 2, 8, 9]. In other words, reinforcement fiber can enhance the strength of polymer composites but generally reduces the erosion resistance.

In our laboratory, we considered the erosion characteristics of hybrid fiber-reinforced polymers and organic high-polymer fiberreinforced unsaturated polyester (UP) resin composites in order to enhance the erosion resistance of existing fiber-reinforced polymers and to develop new FRP materials with high strength and excellent erosion resistance. The results suggest that a hybrid structure of reinforced fiber laminae can improve the erosion resistance [10] and that it is feasible to develop FRP materials with low density, high strength, and excellent erosion resistance by using organic high-polymer fiber as a reinforcement [11].

As we investigated attempts to improve the erosion resistance of polymer matrix, studies of the erosion resistance of particle-filled polymer materials came to our attention as well. V.K. Srivastava [12] investigated the effects of wheat starch on the erosion wear of E-glass fiber-reinforced epoxy resin composite materials. The results show that the erosion rate of GFRPs filled with wheat starch is lower than that of neat GFRP; however, the hardness, tensile strength, and density was lower than with neat GFRP. A similar conclusion was reached for glass-fiber-reinforced fly-ash-filled epoxy resin composites [13].

In recent years, various carbon nanofibers such as vapor-grown carbon fiber (VGCF) and carbon nano-tubes (CNT) have been widely used as reinforcements for polymeric matrices in many high-technology applications and widely investigated in academia because of their outstanding multifunction properties, especially their mechanical properties [14-18]. However, little research has focused on the erosion characteristics of nano-filler composites.

Therefore, we planned to develop nano-filler composites with high strength and outstanding erosion resistance by using a

\footnotetext{
* Corresponding author: E-mail: baolimin@shinshu-u.ac.jp, Tel: +81-268-21-5423
} 
nanomaterial (VGCF) with high strength and high modulus as filler for reinforcing UP resin, which is a representative resin among the thermoset polymers. The present study investigated the effects of the filler weight content, impact angle, and impact velocity upon the erosion-wear characteristics of UP resin. The mechanical properties of composite materials reinforced by VGCF were tested and compared with those of neat UP resin.

\section{EXPERIMENTAL}

\section{Materials}

The polymer matrix used in this study was unsaturated polyester resin (158BQTN), manufactured by Showa Highpolymer Co., Ltd. For comparison, two kinds of nanofillers were used. One was carbon black (CB) (Seast V (GPF)) provided by Tokai Carbon Co., Ltd., with an average particle diameter of $62 \mathrm{~nm}$ and a pour density of $0.47 \mathrm{~g} / \mathrm{cm}^{3}$. The other nano-filler was VGCF, obtained from Showa Denko Japan, with a diameter of $150 \mathrm{~nm}$ and lengths of 10 to $20 \mu \mathrm{m}$ and synthesized by the gas-phase method.

\section{Preparation of nano-filler composites}

Before utilizing the nano-fillers, the VGCF and CB were dried at $80^{\circ} \mathrm{C}$ in a vacuum for $12 \mathrm{~h}$ to remove any water. The VGCF surface was modified by the UV ozone method using lab-made equipment and working at wavelengths of $185 \mathrm{~nm}$ and $254 \mathrm{~nm}$ with a 5 min exposure and an irradiation distance of $1 \mathrm{~cm}$, to improve the interface adhesion between the VGCF and the UP resin.

The dispersion processing of the nano-filler was separated into two steps. First, nanofiller was dispersed into UP resin by a high flex homogenizer (HF 93) manufactured by SMT Co., Ltd., with the stirring process carried out at $4000 \mathrm{rpm}, 8000 \mathrm{rpm}$, and 12,000 $\mathrm{rpm}$ for $90 \mathrm{sec}$ each. The stirring times were increased with the filler weight contents pro rata. Next, the combined mixing process was continued for $15 \mathrm{~min}$ at $1000 \mathrm{rpm}$ using a non-bubbling kneader (NBK-1), produced by Nihonseiki Kaisha Ltd., to remove any bubbles and make the dispersal more uniform. Methyl ethyl ketone peroxide, used as a curing agent, was then added to the mixture and stirred for an additional $5 \mathrm{~min}$. The mixing ratio by weight was 100 parts UP resin to 99 parts curing agent to 1 part accelerator. We carried out the preparations for materials at room temperature. Finally, the mixture was infused into a metal mold to achieve a constant uniform thickness between 2.55 and $2.75 \mathrm{~mm}$. The molding was compacted by a hot pressing machine at a pressure of 8 to $10 \mathrm{MPa}$ at $65^{\circ} \mathrm{C}$ for $4 \mathrm{~h}$, then the specimen was cured at $50^{\circ} \mathrm{C}$ for another $12 \mathrm{~h}$ in a heating oven. The nanocomposite specimens were prepared with contents of $0,1.25$, 2.5 , and $5 \mathrm{wt} \%$ of both VGCF and CB.

\section{Erosion wear testing}

A schematic diagram of the erosion tester is presented in Fig. 1, and the testing conditions are listed in Table 1 .
The specimen was fixed on a metal stage. Solid particles were held in a hopper and fed into an air stream by a vibratory feeder (AD-4826, A\&D Company, Ltd.), which maintains stable, continuous feeding with superior precision. The velocity of the compressed air created by an air compressor (SulesanII, AS4PD-6, Kobe Steel, Ltd. Kobelco) was controlled by adjusting the inlet pressure of the gun nozzle (NAB-11-6, Trusco Nakayama Co., Ltd.). A high-velocity air stream containing solid particles was shot from the nozzle of the air gun and impacted on the surface of the specimen so as to cause erosion wear. Testing was carried out five times for 20 min with each impact angle for each kind of specimen. The weight loss $\left(W_{L}\right)$ that occurred during the erosion testing was measured by an electronic balance (TE214S, Sartorius mechatronics Japan K.K.), in order to evaluate the erosion damage of the FRP materials.

\section{Flexural testing}

Three flexural tests of the FRP composites were conducted using an Auto Graph (AG-20KND) manufactured by Shimadzu Corporation. The testing conditions and the size of the specimen conformed to "JIS K 7171" in the Japanese Industrial Standards. In this study, the specimen was $50 \times 25 \times 2.7 \mathrm{~mm}$ in size, with the fulcrum distance set at $40 \mathrm{~mm}$, and the cross-load speed set to 2 $\mathrm{mm} / \mathrm{min}$ for all five kinds of material.

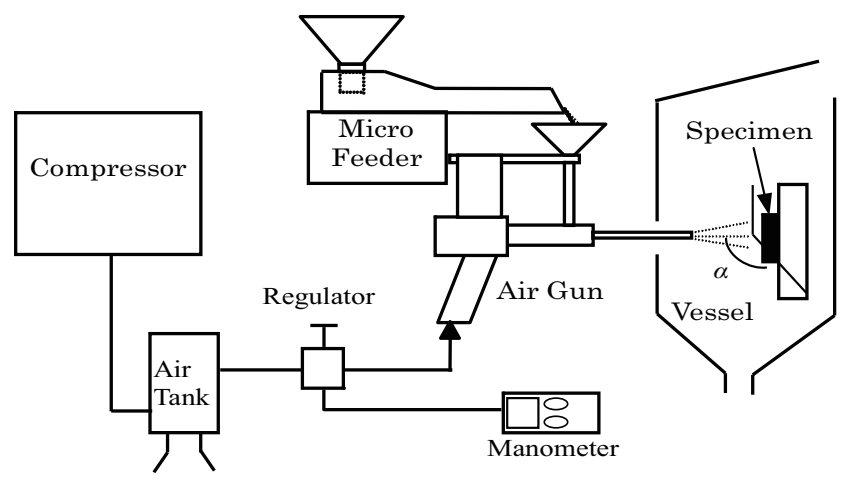

Fig. 1 Schematic diagram of the erosion tester.

Table 1 Erosion test conditions.

\begin{tabular}{cc}
\hline Test parameter & Data \\
\hline Erodent & Alumina solid \\
Erodent size $(\mu \mathrm{m})$ & 11.50 \\
Erodent shape & Angular \\
Impact angle $\left(\alpha^{\circ}\right)$ & $15,30,45,60,75,90$ \\
Impact velocity $(\mathrm{m} / \mathrm{s})$ & $97.8,128,152$ \\
Average erodent feed rate $(\mathrm{g} / \mathrm{min})$ & 40 \\
Nozzle-to-sample distance $(\mathrm{mm})$ & 5.3 \\
Nozzle inner diameter $(\mathrm{mm})$ & 1.80 \\
\hline
\end{tabular}




\section{RESULTS AND DISCUSSION}

\subsection{Effect of UV ozone treatment and dispersal uniformity}

Surface free energy (SFE) is used increasingly as a measure of adhesive properties. An increase in fiber SFE, especially the polar component, is a direct result of introducing polar functional groups onto the fiber surface during UV ozone treatment because the surface of the VGCF becomes highly hydrophilic. Therefore, the wetting characteristics with the treated VGCF were characterized by the liquid penetration level, according to the capillary rise method. The inside diameter of the glass tube is $5 \mathrm{~mm}$. VGCF in the glass tube was compressed with a $10 \mathrm{gf}$ force to be distributed uniformly. After $10 \mathrm{~min}$, penetration level is measured.

Figure 2 graphs the penetration level of VGCF after UV ozone treatment for $1,3,5$, and $7 \mathrm{~min}$, compared with that without treatment. The penetration level of VGCF for $7 \mathrm{~min}$ of UV irradiation time is smaller than that for 5 min of UV irradiation time. The experimental results showed that the optimum irradiation times were obtained at 5 minutes in this surface treatment. It was obvious that the VGCFs without surface treatment were only slightly hydrophilic, and that the penetration characteristics of the treated VGCF samples were all improved, especially those with an irradiation time of $5 \mathrm{~min}$. Oxygen-rich functional groups were formed at the surface of the treated VGCF samples by UV waves, so that the surface became more hydrophilic. Higher penetration levels yielded better adhesive properties for a given UV irradiation time. Surface treated VGCF was used by 5 minutes UV irradiation time in this research. "Although specific changes in the surfaces of treated VGCF samples were identified, as seen in Fig. 2, it was quite clear that the use of UV ozone for VGCF surface modification was successful.

In order to determine the effects of the distribution and quality of

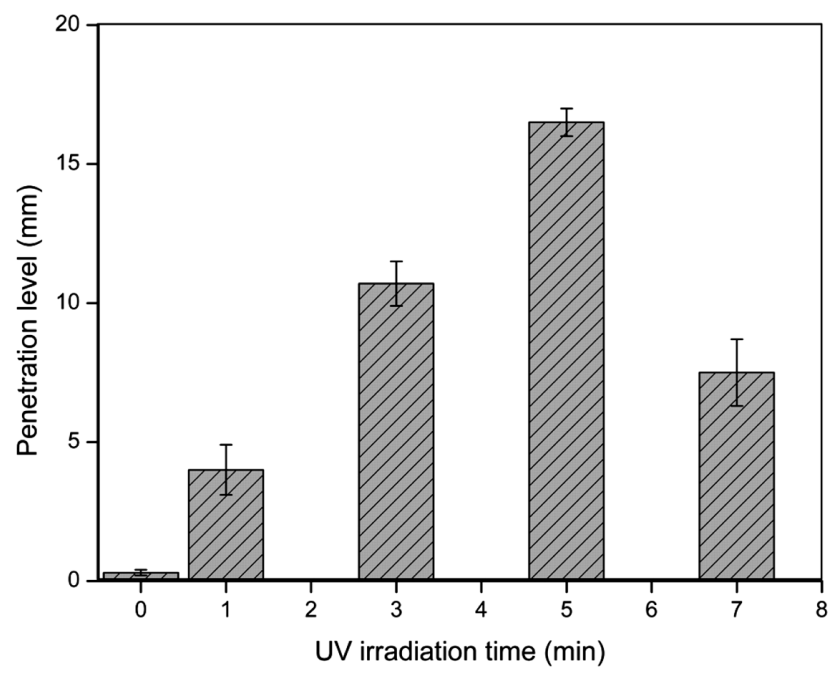

Fig. 2 Variation in the penetration level with UV irradiation time.

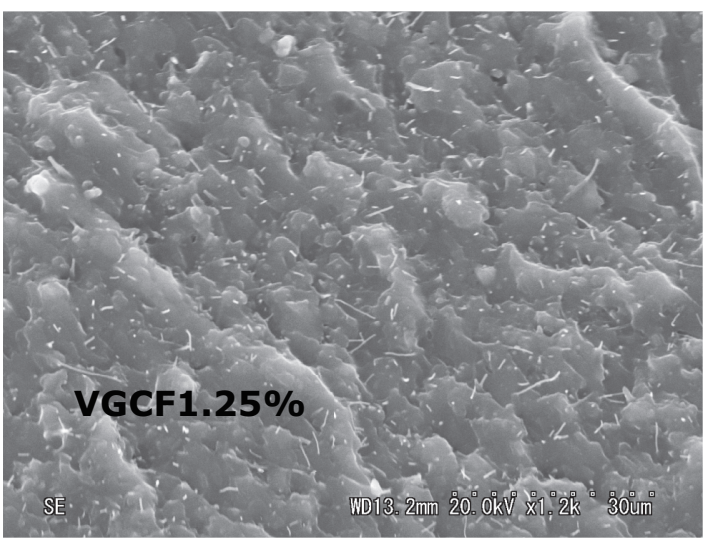

Fig. 3 SEM micrographs of the dispersion of VGCFs in UP resin: $1.25 \mathrm{wt} \%$.

the composite structure, cross-sectional surfaces of the composite UP resin were observed with a scanning electron microscope. The preparatory condition is the same as the nano-filler composites in chapter 2. Figure 3 presents typical SEM images of UP resin filled with VGCF at 1.25. Composite fracture surfaces exhibit a high level of dispersion of the fillers.

\subsection{Effect of filler on mechanical properties}

To compare the mechanical properties of nanofiller composites, three-point flexural testing was carried out for neat UP resin and for composites filled with VGCF at $1.25,2.50$, and $5.00 \mathrm{wt} \%$ and $\mathrm{CB}$ at $1.25 \mathrm{wt} \%$.

Representative flexural load-deflection curves for neat UP resin and its composites are plotted in Fig. 4. The deflections for the UP resin composites were somewhat smaller than those for the neat UP resin samples. Moreover, the graph indicates that a higher filler content produces a lower deflection. There was an evident tendency for the composites to become much more brittle compared to UP resin with increasing filler content, although the resulting composite materials still exhibited ductile properties.

The average flexural strengths and modulus for five kinds of materials are compared in Figs. 5 and 6. It is obvious that both the VGCF- and CB-filled UP resin composites exhibited higher flexural strength and flexural modulus values than neat UP resin. The results indicate that both the flexural strength and the modulus were influenced by the filler, and that they were enhanced by an increase in the filler content, especially VGCF. Overall, the flexural strength increased by $17 \%$ and the flexural modulus increased by $48 \%$ in $5.00 \mathrm{wt} \%$ VGCF-filled composites as compared to neat UP resin.

It is well known that there is little influence due to the interface adhesive strength and few effects such as filler surface treatment, because the mechanical modulus corresponds to the initial phase of deformation. Thus, it was confirmed that VGCF and $\mathrm{CB}$ can fill the UP resin without decreasing the modulus. As seen in Figs. 5 and 6, 


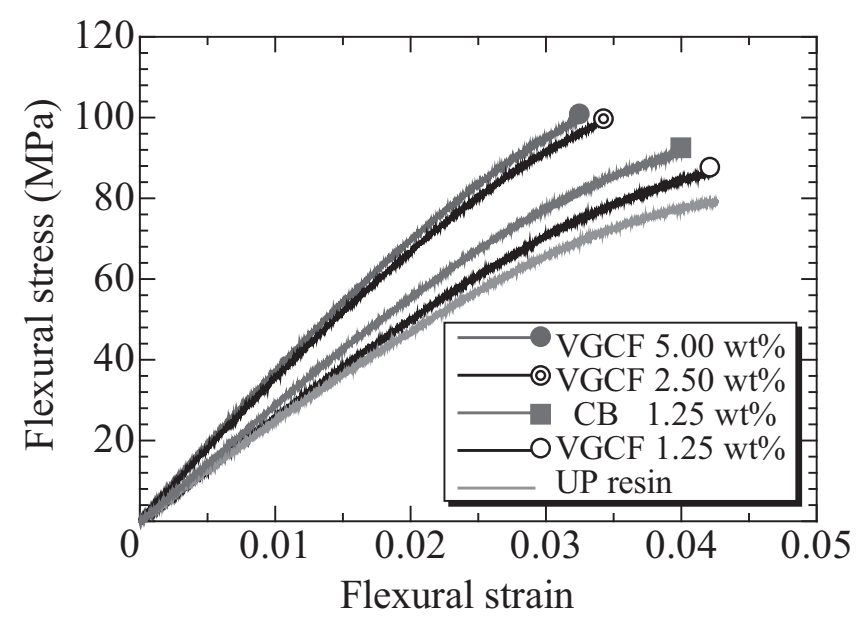

Fig. 4 Flexural load and deflection curves for UP resin filled with various nano-fillers.

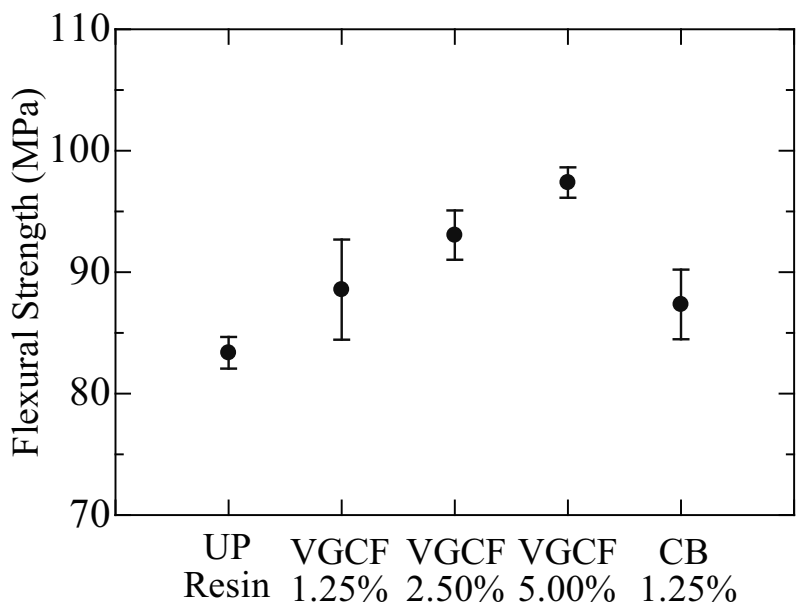

Fig. 5 Comparison of flexural strength of neat UP resin and its nano-filler composites.

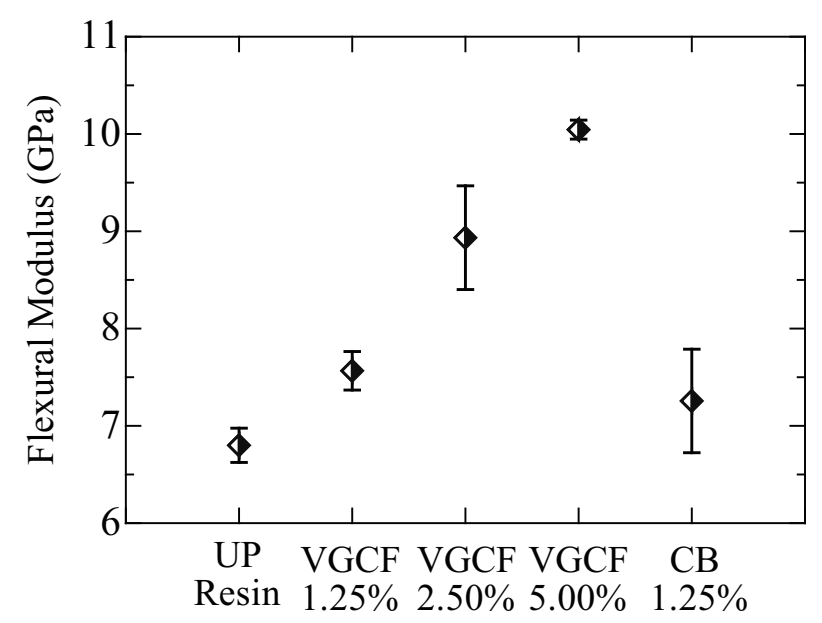

Fig. 6 Comparison of the flexural modulus of neat UP resin and its nano-filler composites. the strength and modulus of polymer materials can be reinforced by nanofillers with excellent mechanical properties, and there are relatively few micro-structural defects in the composites as long as the nanofillers are dispersed with sufficient uniformity.

As mentioned in the introduction, fillers such as wheat starch and fly ash improve the erosion resistance of GFRP but also reduce its mechanical strength [12]. However, the results of our study indicate that both the erosion resistance and mechanical strength of polymer composites could be increased simultaneously by using highstrength nano-fillers like VGCF and CB.

\subsection{Effect of fillers on erosion wear}

Numerous factors influence the erosion wear of materials, but the most important are the impact velocity; the impact angle of the particles; and the size, shape, and hardness of the particles. This study examined only the effect of the impact angle and three levels of impact velocity.

In order to quantify the extent of the damage, the erosion rate of weight loss $(E r)$ is expressed as the weight of material removed by a unit weight of impacting particles in the following equation:

$$
E r=\frac{W_{L}(g)}{W_{S}(g)}
$$

where $W_{L}$ is the weight loss of the specimen and $W_{s}$ is the total weight of the impacting particles over 20 minutes.

A lower erosion rate indicates better erosion resistance in the tested materials.

Figure 7 plots the variation in the erosion rate in terms of the weight loss of UP resin filled with VGCF at impact angles from $15^{\circ}$ to $90^{\circ}$. The impact velocity is $128 \mathrm{~m} / \mathrm{s}$. The erosion rates at lower impact angles $\left(15^{\circ}\right.$ to $\left.45^{\circ}\right)$ were much higher than those at higher impact angles $\left(60^{\circ}\right.$ to $\left.90^{\circ}\right)$, and the maximum erosion rate occurred at an impact angle between $30^{\circ}$ and $45^{\circ}$ for two kinds of materials. The erosion rate at $30^{\circ}$ was nearly 1.7 times that at $90^{\circ}$. The

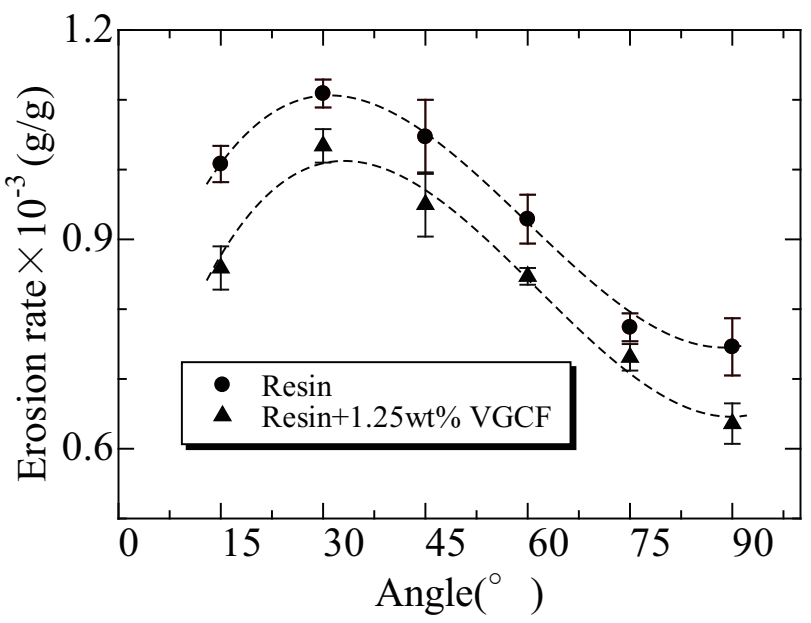

Fig. 7 Impact angles - Erosion rate for VGCF and resin only. (Impact velocity $128 \mathrm{~m} / \mathrm{s}$ ) 
erosion rate is strongly affected by the variation in the impact angles of the particles. It was observed that UP resin gave a higher value than VGCF-filled UP resin composites at all impact angles; the distinction was appreciable with the VGCF fillers. This indicates that the erosion resistance of the resin matrix can be improved by using VGCF filler.

The variation in the erosion rate of CB-filled UP resin composites as a function of impact angles ranging from $15^{\circ}$ to $90^{\circ}$ is plotted in Fig. 8. All composite samples exhibited similar characteristics, namely those of a typical ductile material in which the maximum erosion rates were at impact angles between $30^{\circ}$ and $45^{\circ}$, as indicated in Fig. 7. This is because of the constitution of materials mainly is UP resin.

These results are in agreement with those of previous investigations [19, 20], with ductile materials exhibiting maximum erosion or weight loss after being exposed to an impact angle of about $30^{\circ}$. Increasing the impact angle decreased the erosion to a minimum value at normal incidence. The erosion rates of CB-filled UP resin composites were obviously much lower than those of neat UP resin. In other words, the erosion resistance of VGCF- and CBfilled UP resin is superior to that of neat UP resin.

In addition, as seen in both Fig. 7 and Fig. 8 with respect to VGCF and CB fillers, these high-strength nanofillers remarkably improved the erosion resistance of UP resin. In the studies of V. K. Srivastava et al. $[12,13]$ on the effects of wheat starch and fly ash, these soft fillers enhanced the erosion resistance of glass-fiberreinforced epoxy resin composite materials, based on the fact that the bonding strength of the interface between matrix and fiber was higher and thus could sustain greater damage than could neat GFRP. The results of our study indicate the same trends with respect to the erosion resistance of composites filled with highstrength, high-modulus nano-fillers.

Figure 9 illustrates the relation between erosion rate and VGCF weight fraction. The erosion rate did not increase with an increase

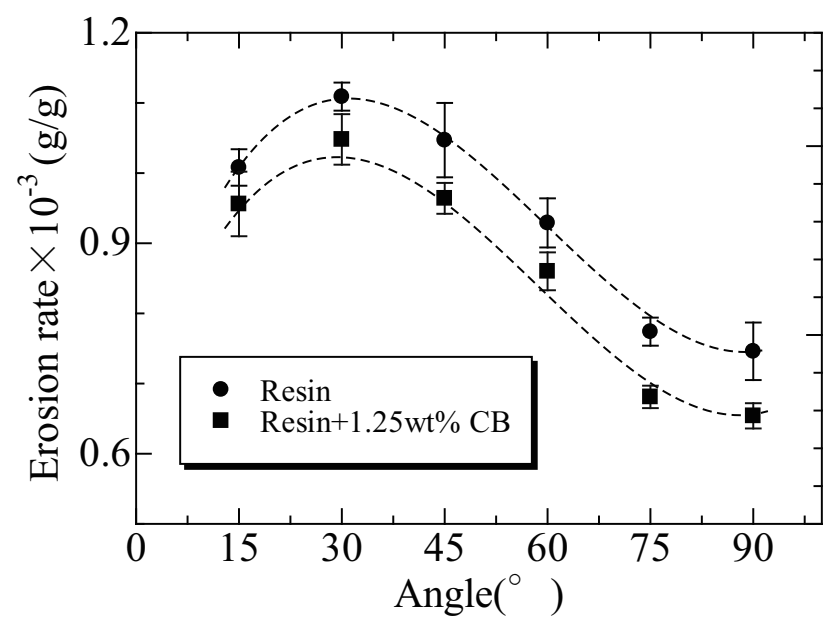

Fig. 8 Impact angles - Erosion rate for CB and resin only. (Impact velocity $128 \mathrm{~m} / \mathrm{s}$ ) in VGCF weight fraction, as seen in Fig. 9. Although the distinctions among the VGCF-filled composites are not very clear, the $1.25 \mathrm{wt} \%$ VGCF-filled UP resin samples still exhibited a higher erosion resistance than the 2.50 and $5 \mathrm{wt} \%$ VGCF-filled UP resin composites. The erosion rate of VGCF-filled composites is slightly lower than that of $\mathrm{CB}$-filled composites.

The impact velocity is one of the most important factors influencing the erosion rate of materials. Figure 10 compares the effects of three levels of impact velocity on the erosion rate of composites filled with various VGCF contents. For neat UP resin, the erosion rate varied from 0.892 to $1.922 \%$ for the various impact velocities. The erosion rate almost doubled when the impact velocity was only increased from 97.8 to $152 \mathrm{~m} / \mathrm{s}$, indicating that the erosion rate $(E r)$ increased exponentially with the impact velocity $(V)$, a relation which could be expressed as $E r \propto V^{n}$. The value of $\mathrm{n}$ was calculated to be about 1.6575 . There were similar trends for the VGCF-filled UP resin composites. Though the

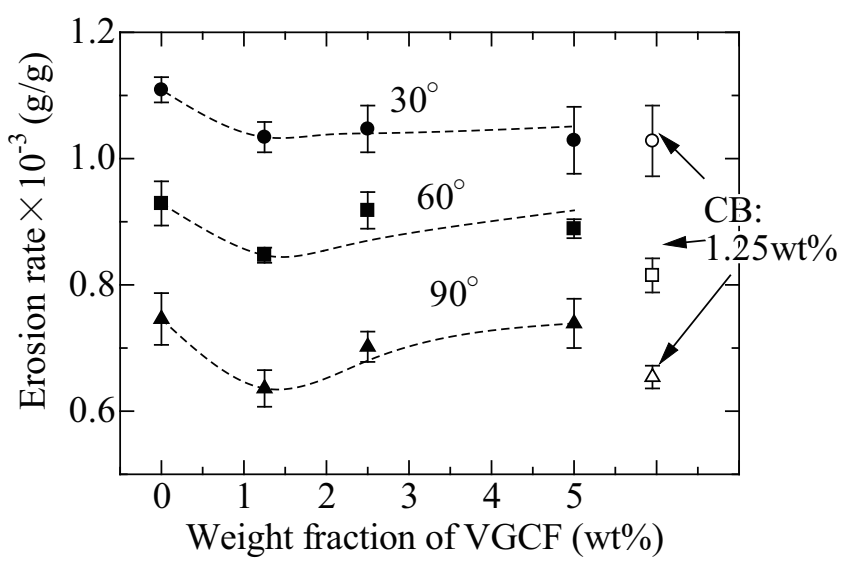

Fig. 9 Erosion rate of UP resin filled with various VGCF weight fractions. (Impact velocity $128 \mathrm{~m} / \mathrm{s}$ )

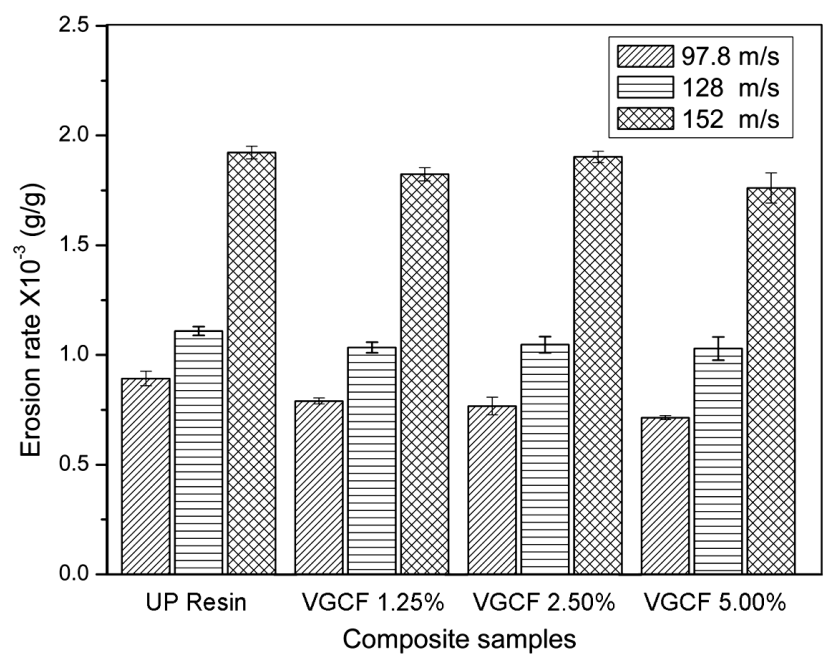

Fig. 10 Bar diagram of the erosion rate of composites filled with VGCF at an impact angle of $30^{\circ}$ with various impact velocities. 
erosion rates were slightly lower, the erosion rates of filled composites were lower than those of neat UP at all impact velocities. The influence of the filler content on the erosion resistance was plainly visible at a velocity of $97.8 \mathrm{~m} / \mathrm{s}$. At a velocity of $128 \mathrm{~m} / \mathrm{s}, 1.25 \mathrm{wt} \%$ VGCF-filled composites exhibited greater erosion resistance than the others.

Figure 11 presents SEM micrographs of eroded surfaces of UP resin composites filled with $\mathrm{VGCF}$ and $\mathrm{CB}$ at a weight content of $1.25 \mathrm{wt} \%$ and at an impact velocity of $128 \mathrm{~m} / \mathrm{s}$. The micrographs suggest that the resin matrix of the composites exhibited mainly ductile damage, which is also illustrated in Figs. 8 and 9. In this study, there were no reinforcement continuous fibers in the composite materials, so it is believed that the local removal of resin matrix from the impacted surface was the main erosion damage. The interface between the resin and VGCF remained stable even after the impact of the particles, indicating that the interface adhesive was sufficient. For resin materials, most of the damage occurred in the area of the resin matrix, where micro-cutting and cracks appeared and developed. VGCF and CB were much stronger than the resin matrix. These resulted in the restriction of damage development and a reduction in the removal rate of the resin from
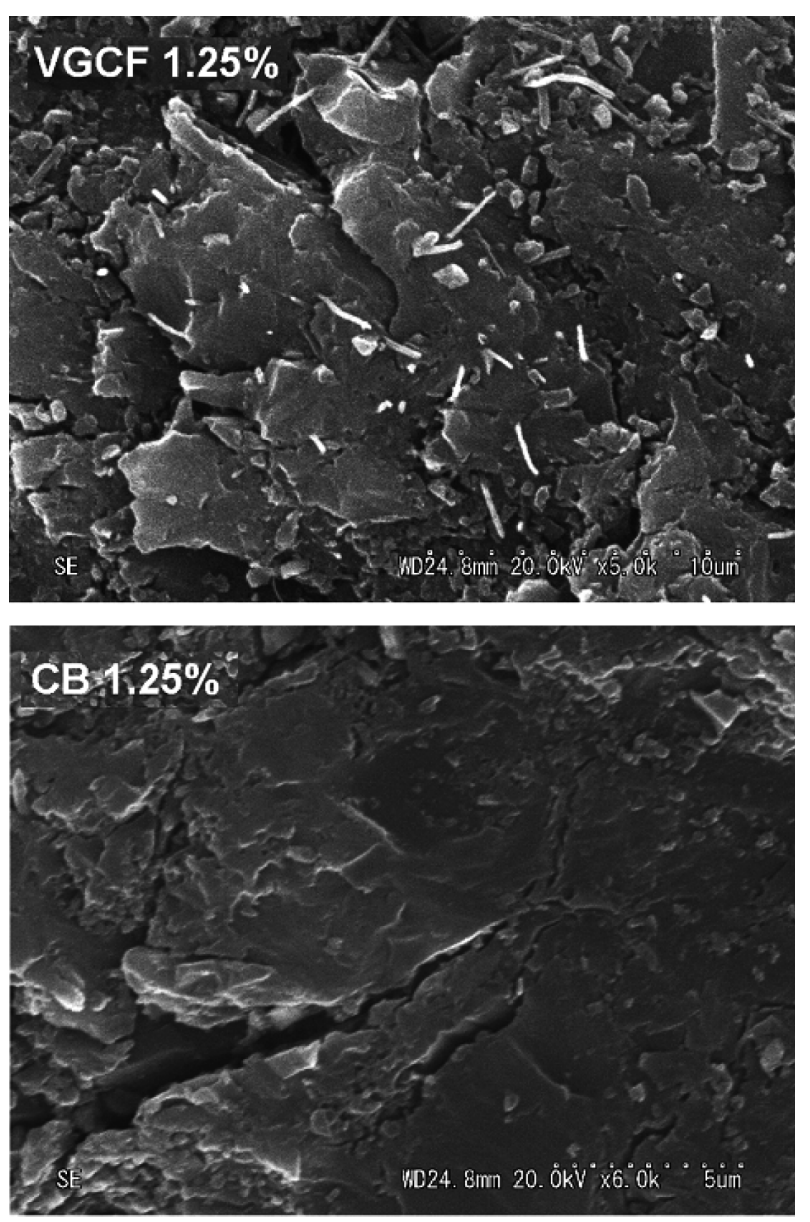

Fig. 11 SEM micrographs of eroded surfaces of UP resin composites filled with VGCF and $\mathrm{CB}$ at weight content of $1.25 \%$ (at an impact velocity of $128 \mathrm{~m} / \mathrm{s}$ ) the materials. The resistance to crack development was improved, as the crack extremity curved between particles in CB-filled UP resin composites. Since VGCFs have a high specific surface area, it is possible to conjecture that the VGCF formed a network structure that reinforced the resin matrix in the composites. For the resistance to crack development, the effect of VGCF exceeds that of CB. Therefore, for these reasons, the erosion resistance of the VGCFfilled composites was better than that of neat UP resin.

\section{CONCLUSIONS}

Experiments were carried out to study the effect of VGCF and $\mathrm{CB}$ filler materials (nanofiller) on the erosion characteristic of UP resin composites. The flexural properties were compared as well.

The flexural strength and modulus of VGCF- and CB-filled UP resin composites were enhanced significantly compared with neat UP resin.

The erosion resistance of UP resin was improved with nanofillers of VGCF and $\mathrm{CB}$ at all impact angles. The influence of the impact angle on erosion wear for all composites exhibited typical ductile erosion wear characteristics with a maximum erosion rate at $30^{\circ}$. A UP resin composite filled with VGCF of $1.25 \mathrm{wt} \%$ exhibited higher erosion resistance than those of 2.50 and $5.00 \mathrm{wt} \%$.

These findings are the first step to uncover mechanism for erosion of materials which filled with the filler that is smaller than a collision particle. Additional research of the interface and size's effects are needed.

\section{Acknowledgments}

This work was supported by a Grant-in-Aid for the Global COE Program and Scientific Research (C)(2) 16560067 by the Ministry of Education, Culture, Sports, Science, and Technology.

\section{References}

[1] Harsha A, Tewari U, Venkatraman B (2003) Wear, 254, 693-712

[2] Barkoula N, Karger J (2002) Wear, 252, 80-87

[3] Tewari U, Harsha A, Häger A, Friedrich K (2002) Wear, 252, 992-1000

[4] Sarı N, Sinmazcelik T (2007) Materials \& Design, 28, 351-355

[5] Tewari U, Harsha A, Häger A, Friedrich K (2003) Compos Sci Technol, 63, 549-557

[6] Tsuda K, Kubouchi M, Sakai T, Saputra A, Mitomo N (2006) Wear, 260, 1045-1052

[7] Pallout Y, Hovis S, Talia J (1990) Wear, 24, 195-200

[8] Miyazaki N, Takeda N (1994) J Compos Mater, 28, 871-876

[9] Häger A, Friedrich K, Dzenis Y, Paipetis S (1995) Proceedings of the ICCM-10, Canada, 155-162

[10] Qian D, Bao L, Takatera M, Kemmochi K (2009) J Text Eng, 
55, 39-44

[11] Qian D, Bao L, Takatera M, Kemmochi K, Yamanaka A (2010) Wear, 268, 637-642

[12] Srivastava S (2006) Mater Sci Eng A, 435-436, 282-287

[13] Srivastava V, Pawar A (2006) Compos Sci Technol, 66, 3021-3028

[14] Cho J, Joshi M, Sun C (2006) Compos Sci Technol, 66, 1941-1952

[15] F. IED (1995) 'Interface Control and Design of Composites', pp170-230, Sigma, Japan
[16] Zhang L, Ni Q, Shiga A, Fu Y, Natsuki T (2010) Polym Compos, 31, 491-493

[17] Choi Y, Sugimoto K, Song S, Gotoh Y, Ohkoshi Y, Endo M (2005) Carbon, 43, 2199-2204

[18] Miyagawa H, Drzal L (2005) Composites: Part A, 36, 1440-1446

[19] Tilly G (1969) Wear, 14, 63-79

[20] Barkoula N, Karger-Kocsis J (2002) J Reinf Plast Compos, 21, 1377-1388 